\title{
Is Endoscopic Resection for Type 1 Gastric Neuroendocrine Tumors Essential for Treatment?: Multicenter, Retrospective Long-term Follow-up Results
}

\author{
Han Sol Lee, Seong Woo Jeon, Gwang Ha Kim', Jin Il Kim², Il-Kwun Chung ${ }^{3}$, Sam Ryong Jee ${ }^{4}$, Heung Up Kim ${ }^{5}$, Geom Seog Seo ${ }^{6}$, \\ Gwang Ho Baik ${ }^{7}$, Kee Don Choi ${ }^{8}$, Jeong Seop Moon ${ }^{9}$ \\ Department of Internal Medicine, Kyungpook National University Medical Center, Daegu, Department of Internal Medicine, Pusan National \\ University School of Medicine ${ }^{1}$, Busan, Department of Internal Medicine, College of Medicine, The Catholic University of Korea ${ }^{2}$, Seoul, \\ Department of Internal Medicine, Soonchunhyang University College of Medicine ${ }^{3}$. Cheonan, Department of Internal Medicine, Inje \\ University Pusan Paik Hospital ${ }^{4}$, Busan, Department of Internal Medicine, Jeju National University School of Medicine ${ }^{5}$, Jeju, Department of \\ Internal Medicine, Digestive Disease Research Institute, Wonkwang University College of Medicine, Iksan, Department of Internal Medicine, \\ Hallym University College of Medicine, Chuncheon, Department of Internal Medicine, Asan Medical Center, University of Ulsan College of \\ Medicine ${ }^{8}$, Seoul, Department of Internal Medicine, Inje University Seoul Paik Hospital ${ }^{9}$, Seoul, Korea
}

Background/Aims: Treatment of gastric neuroendocrine tumors is determined by type and size of the lesion. This study aimed to compare the long-term efficacy of observation and endoscopic resection for type 1 gastric neuroendocrine tumors without metastasis.

Materials and Methods: Among the 223 cases of gastric neuroendocrine tumors diagnosed between January 1996 and December 2011, 104 cases were type 1 gastric neuroendocrine tumors. Sixty-seven patients were treated endoscopically and 27 patients were observed without treatment. Endoscopic mucosal resection, endoscopic submucosal dissection, and polypectomy were the methods used for endoscopic treatment. Therapeutic efficacy and rates of complication and recurrence were evaluated retrospectively. Results: In the endoscopic resection group, complete resection was observed in 53 patients (79.1\%), and recurrence was observed in 14 patients $(20.9 \%)$. On analysis of the observation group, no change was observed in 19 patients $(70.4 \%)$, and tumor progression was observed in 8 patients (29.6\%). Median follow-up duration was 49 months (31 210 months). No mortality was reported in either group during follow-up.

Conclusions: Observation of type 1 gastric neuroendocrine tumors without metastasis yields results similar to those produced by endoscopic resection. Observation alone may be a safe treatment. (Korean J Helicobacter Up Gastrointest Res 2016;16:13-18)

Key Words: Stomach; Neuroendocrine tumors; Endoscopy; Observation; Treatment

\section{INTRODUCTION}

Gastric neuroendocrine tumors (NETs), which are relatively rare tumors that arise from enterochromaffin cells, have been reported increasingly in the last decade. ${ }^{1-3}$ They are classified into 3 types, each with different pathophysiology and prognosis. ${ }^{3-5}$

Type 1 is the most common type of gastric NET, occurring in $70 \sim 80 \%$ of cases. Type 1 NETs are associated with raised gastrin levels and arise from enterochromaffin-like cells in autoimmune-related pernicious anemia and type A chronic atrophic gastritis. ${ }^{6-8}$ Most gastric NETs are found

Received: December 28, 2015 Accepted: March 2, 2016

Corresponding author: Seong Woo Jeon

Department of Internal Medicine, Kyungpook National University Medical Center, 807 Hoguk-ro, Buk-gu, Daegu 41404, Korea

Tel: +82-53-200-2602, Fax: +82-53-200-2027, E-mail: swjeon@knu.ac.kr incidentally when esophagogastroduodenoscopy is performed. In many cases, endoscopic resection or conservative treatment is performed, especially in cases of tumors smaller than $20 \mathrm{~mm}$ without vascular invasion or proper muscle infiltration. ${ }^{7,8}$ Still, endoscopic resection in cases of type 1 gastric NETs is controversial., And, no comparative study of endoscopic resection vs. observation of type 1 gastric NETs has been performed.

We performed a retrospective case review to determine the outcome and long-term prognosis between observation and endoscopic resection of type 1 gastric NETs.

\section{MATERIALS AND METHODS}

\section{Patients}

Members of the Korean College of Helicobacter and

Copyright $\odot 2016$ Korean College of Helicobacter and Upper Gastrointestinal Research

(ङ) The Korean Journal of Helicobacter and Upper Gastrointestinal Research is an Open-Access Journal. All articles are distributed under the terms of the Creative Commons Attribution Non-Commercial License (http://creativecommons.org/licenses/by-nc/4.0) which permits unrestricted non-commercial use, distribution, and reproduction in any medium, provided the original work is properly cited. 
Upper Gastrointestinal Research enrolled patients with histologically proven type 1 gastric NETs from 10 hospitals between January 1996 and December 2011. Gastric NETs were classified according to the Paris endoscopic classification. $^{9}$ An additional imaging study (e.g., CT scan) was performed for diagnosis of lymph node involvement or metastasis. In addition, endoscopic ultrasound was performed to determine tumor size and depth of infiltration. Patients' symptoms, associated disease, tumor characteristics, and outcome following treatment were analyzed. To classify tumors as type 1 gastric NETs, patients' plasma gastrin levels were analyzed and other associations, such as Zollinger-Ellison syndrome or multiple endocrine neoplasia type 1 , were ruled out.

This study was carried out in accordance with the Declaration of Helsinki (2000) of the World Medical Association and was approved by University Hospital Kyungpook Trust (KNUMC_12-1005) and the institutional review board of each center.

We divided the enrolled patients into two groups according to treatment modalities: endoscopic resection group (ER group) and observation only group (OB group).

\section{Endoscopic resection}

Tumor size and number and location were measured on the basis of endoscopic reports and images. An approximately 6-mm sized biopsy forceps (FB-21K-1; Olympus Medical Systems Co., Tokyo, Japan) was used to estimate tumor size. After informed consent was received, endoscopic resection was performed by endoscopic mucosal resection (EMR), endoscopic submucosal dissection (ESD), or polypectomy.

Regular follow-up examination with endoscopy was performed at regular intervals according to each center's policy. Also, CT scan and blood tests were performed on most of the patients. Recurrence in the ER group was defined as new NETs diagnosed on follow-up endoscopy. In the OB group, tumor progression was defined when tumor number or size increased on follow-up endoscopic examinations.

\section{Histopathologic findings and stage of gastric NETs}

Resected specimens were fixed with formalin and sec- tioned at 2-mm intervals. Tissue slides were made, and tumor involvement in the lateral and vertical margins was assessed. Also, histopathological type, invasion depth, size, and lymphovascular invasion were observed microscopically. The definition of pathological complete resection was set according to the following findings: en bloc resection, well-differentiated neuroendocrine tumor according to World Health Organization (WHO) classification, tumor invasion limited to the submucosal layer, no lateral and vertical margin involvement, and no lymphovascular invasion. ${ }^{6,10-12}$

\section{Statistical analysis}

Continuous variable data are presented as mean $\pm \mathrm{SD}$. Unpaired Student's t-test was used to calculate statistical significance. Univariate analysis with Student's t-test was used to assess the difference between the ER and OB groups. Statistical significance was set at 0.05 , and statistical analysis was performed using PASW Statistics version 18.0 (IBM Co., Armonk, NY, USA).

\section{RESULTS}

\section{Patient characteristics}

Among 223 patients with gastric NETs diagnosed between January 1996 and December 2011, 104 patients with type 1 gastric NETs were identified in the databases from 10 hospitals. Ten patients were lost to follow-up, and the remaining 94 patients were enrolled in this study. Of the 94 patients, 53 patients (56.4\%) were male, and the average age was 54.9 years (30 80 years). The majority of the patients $(70.2 \%)$ had no symptoms, and abdominal discomfort was the second symptom (29.8\%). Seven patients (7.4\%) had diabetes mellitus (DM), 6 patients (6.4\%) had thyroid disease, and 1 patient (1.1\%) had combined early gastric cancer and autoimmune disease. Also, 3 patients each (3.2\%) had another malignancy and combined diseases, such as DM with thyroid disease (Table 1).

\section{Study flow and results}

Among 94 patients, endoscopic resection was performed in 67 patients $(71.3 \%)$ for treatment of type 1 gas- 
Table 1. Patient Characteristics of 94 Type 1 Gastric Neuroendocrine Tumors

\begin{tabular}{|c|c|}
\hline Characteristic & Value \\
\hline Male:female & $53: 41(56.4: 43.6)$ \\
\hline Mean age (yr) & $54.9 \pm 11.3$ \\
\hline \multicolumn{2}{|l|}{ Associated symptoms } \\
\hline No symptom & $66(70.2)$ \\
\hline Abdominal discomfort & $28(29.8)$ \\
\hline \multicolumn{2}{|l|}{ Associated disease } \\
\hline No other disease & $73(77.6)$ \\
\hline Diabetes mellitus & $7(7.4)$ \\
\hline Thyroid disease & $6(6.4)$ \\
\hline Combined EGC & $1(1.1)$ \\
\hline Other autoimmune disease & $1(1.1)$ \\
\hline Combined other malignancy & $3(3.2)$ \\
\hline $\mathrm{DM}+$ thyroid disease & $3(3.2)$ \\
\hline \multicolumn{2}{|l|}{ Number of tumors } \\
\hline 1 & 74 (78.7) \\
\hline $2 \sim 5$ & $14(14.9)$ \\
\hline $6 \sim 10$ & $5(5.3)$ \\
\hline$>10$ & $1(1.1)$ \\
\hline \multicolumn{2}{|l|}{ Tumor location } \\
\hline Antrum & $9(9.6)$ \\
\hline Body & $76(80.9)$ \\
\hline Fundus or cardia & $9(9.6)$ \\
\hline \multicolumn{2}{|l|}{ Tumor size (mm) } \\
\hline$\leq 10$ & $82(87.2)$ \\
\hline$>10$ & $12(12.8)$ \\
\hline \multicolumn{2}{|l|}{ Treatment methods } \\
\hline EMR & $52(55.3)$ \\
\hline ESD & $11(11.7)$ \\
\hline Polypectomy & $4(4.3)$ \\
\hline Observation & $27(28.7)$ \\
\hline \multicolumn{2}{|l|}{ Complete resection } \\
\hline $\operatorname{EMR}(n=52)$ & $43(82.7)$ \\
\hline $\operatorname{ESD}(n=11)$ & $10(90.9)$ \\
\hline Polypectomy $(n=4)$ & $3(75.0)$ \\
\hline Gastrin $(\mathrm{pg} / \mathrm{mL})$ & 474.1 \pm 433.3 , median: 367.3 \\
\hline \multicolumn{2}{|c|}{ Helicobacter pylori (histology, CLO, UBT) } \\
\hline Positive & $17(18.1)$ \\
\hline Negative & $29(30.9)$ \\
\hline Not checked & $48(51.1)$ \\
\hline \multicolumn{2}{|l|}{ Anti-parietal antibody } \\
\hline Positive & $13(13.8)$ \\
\hline Negative & $5(5.3)$ \\
\hline Not checked & $76(80.9)$ \\
\hline Metastasis & $0(0)$ \\
\hline
\end{tabular}

Values are presented as $\mathrm{n}(\%)$ or mean $\pm \mathrm{SD}$.

EGC, early gastric cancer; DM, diabetes mellitus; EMR, endoscopic mucosal resection; ESD, endoscopic submucosal dissection; CLO, campylobacter-like organism test; UBT, urea breath test.

tric NETs (Fig. 1). Seventy-six patients (80.9\%) had tumor on the gastric body, and solitary tumor was the most common type (74 patients, $78.7 \%$ ). Lesion size was less than $10 \mathrm{~mm}$ in 82 patients $(87.2 \%)$. No metastases were found in these patients (Table 1).

\section{Endoscopic characteristics of two groups}

Of 67 patients in whom ER group was performed, 52 (55.3\%) had EMR, 11 (11.7\%) had ESD, and 4 (4.3\%) had polypectomy. Mean tumor size in the $\mathrm{OB}$ group was $6.04 \pm 4.07 \mathrm{~mm}$, and was $7.33 \pm 3.62 \mathrm{~mm}$ in the ER group $(P=0.135)$. Tumor size was greater than $10 \mathrm{~mm}$ in $4 \mathrm{pa}^{-}$ tients $(14.8 \%)$ in the $\mathrm{OB}$ group and 8 patients (11.9\%) in the ER group $(P=0.748)$. No tumors were larger than 20 $\mathrm{mm}$, and no significant difference was seen in tumor location $(P=0.236)$ (Table 2$)$.

\section{Long-term results of two groups}

In the ER group, a complete response was observed in 53 patients (79.1\%), and local recurrence without metastasis was observed in 14 patients (20.9\%). On analysis of the $\mathrm{OB}$ group, no change was observed in 19 patients (70.4\%), but tumor size progression without metastasis was observed in 8 patients (29.6\%). Tumor size progression in the $\mathrm{OB}$ group was observed in 1 to 82 months (median, 11 months) follow-up study. Patients with local recurrence in the ER group and with tumor size progression in the $\mathrm{OB}$ group were treated with endoscopic resection at following studies. Median follow-up duration was 49 months (31 210 months). No mortality was reported in either group during follow-up (Table 3).

\section{DISCUSSION}

Currently, most gastric NETs are diagnosed and treated at an early stage due to early access to screening endoscopy. ${ }^{8,10}$ Recognition of the type of gastric NET is important for determining treatment. ${ }^{3,13,14}$ Because of possibility regarding malignant potential, the treatment approach for types 2 and 3 gastric NETs is well-defined as endoscopic or surgical resection. ${ }^{3,8,14}$ However, treatment of type 1 gastric NETs has remained controversial because they are usually thought to be benign. 7,15

In consideration of the benign character of type 1 gastric NETs, we presumed that observation only approach would be a satisfactory treatment option. In this multi- 


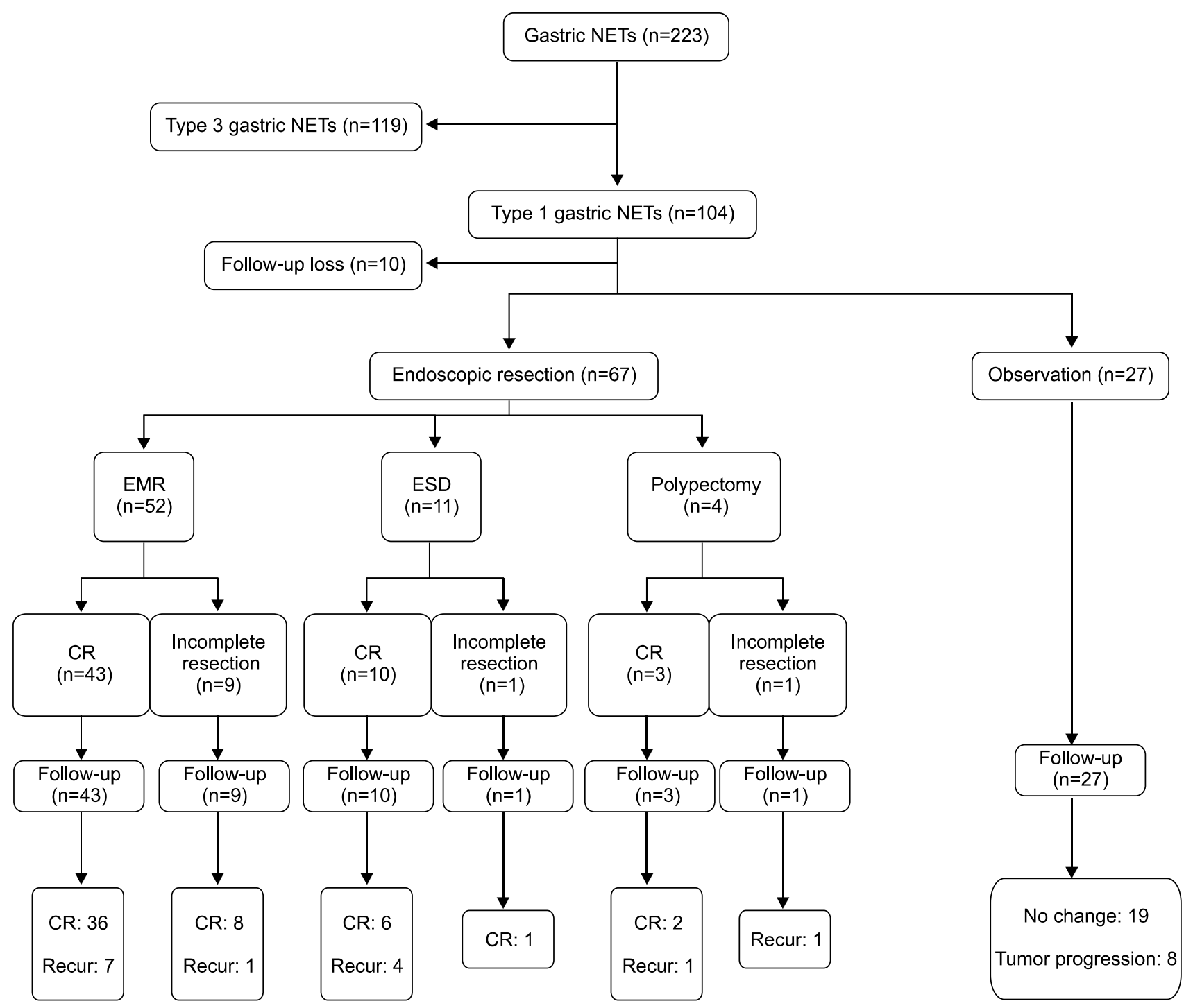

Fig. 1. Flow chart of type 1 gastric neuroendocrine tumors. Of all type 1 gastric neuroendocrine tumors $(n=104), 67$ patients were treated with endoscopic resection, and 27 patients were observed without intervention. In the endoscopic resection group, 52 patients were treated with endoscopic mucosal resection (EMR), 11 patients were treated with endoscopic submucosal dissection (ESD), and 4 patients were treated with polypectomy. Upon analysis of long-term follow-up results, recurrence (Recur) was observed in 14 patients who underwent endoscopic resection, and tumor progression was found in 8 patients who were observed without intervention. NETs, neuroendocrine tumors; CR, complete resection.

Table 2. Tumor Characteristics of the Observation Only and Endoscopic Resection Groups

\begin{tabular}{lrcc}
\hline & $\begin{array}{c}\text { Observation } \\
\text { only }(\mathrm{n}=27)\end{array}$ & $\begin{array}{c}\text { Endoscopic } \\
\text { resection }(\mathrm{n}=67)\end{array}$ & $\begin{array}{c}P \\
\text { value }\end{array}$ \\
\hline Endoscopic tumor size (mm) & $6.04 \pm 4.07$ & $7.33 \pm 3.62$ & 0.135 \\
Tumor size $>10 \mathrm{~mm}$ & $4(14.8)$ & $8(11.9)$ & 0.748 \\
Tumor location & & & 0.236 \\
$\quad$ Antrum & $4(14.8)$ & $5(7.5)$ & \\
$\quad$ Body & $19(70.4)$ & $57(85.1)$ & \\
$\quad$ Fundus or cardia & $4(14.8)$ & $5(7.5)$ & \\
\hline
\end{tabular}

Values are presented as mean $\pm \mathrm{SD}$ or $\mathrm{n}(\%)$. center retrospective study, we disclosed the efficacy of following up without intervention in cases of type 1 gastric NETs. We analyzed the efficacy of observation without tumor resection compared with endoscopic resection in 94 patients. Tumor recurrence/progression and complete response ratio showed no significant difference in the two modality groups in this study.

Until now, many studies have focused on comparing the treatment efficacy of endoscopic resection with surgery in 
Table 3. Analysis of Long-term Treatment Outcomes between Observation Only and Endoscopic Resection Groups

\begin{tabular}{|c|c|c|c|}
\hline & $\begin{array}{l}\text { Observation } \\
\text { only }(n=27)\end{array}$ & $\begin{array}{l}\text { Endoscopic } \\
\text { resection }(n=67)\end{array}$ & $\begin{array}{c}P \\
\text { value }\end{array}$ \\
\hline Tumor progression & $8(29.6)$ & - & \multirow{5}{*}{0.365} \\
\hline Recurrence & & $14(20.9)$ & \\
\hline EMR & - & 8 & \\
\hline ESD & - & 4 & \\
\hline Polypectomy & - & 2 & \\
\hline $\mathrm{CR} /$ no change & $19(70.4)$ & $53(79.1)$ & \\
\hline \multicolumn{4}{|l|}{ Tumor size $(\mathrm{mm})$} \\
\hline Tumor progression & & & 0.976 \\
\hline No $(n=19)$ & $6.05 \pm 4.12$ & - & \\
\hline Yes $(n=8)$ & $6.00 \pm 4.24$ & - & \\
\hline Recurrence & & & 0.245 \\
\hline No $(n=53)$ & - & $7.59 \pm 3.76$ & \\
\hline Yes $(n=14)$ & - & $6.32 \pm 2.93$ & \\
\hline
\end{tabular}

Values are presented as $\mathrm{n}(\%), \mathrm{n}$ only, or mean $\pm \mathrm{SD}$.

EMR, endoscopic mucosal resection; ESD, endoscopic submucosal dissection; CR, complete response.

cases of type 1 gastric NETs. Recently, a few studies recommended conservative treatment by endoscopic monitoring because of the excellent prognosis of type 1 gastric NETs. One of the studies recommended that gastric NETs $10 \mathrm{~mm}$ or smaller in size be managed either by local endoscopic removal or conservatively with endoscopic surveillance in cases with no risk factors (i.e., angioinvasion, G2 G3 histological grading, infiltration of the muscularis propria, size $>20 \mathrm{~mm}$, or metastatic spread). ${ }^{2}$ For $10-$ to 20-mm sized NETs without risk factors, they recommended endoscopic removal and endoscopic surveillance at 1- or 2-year intervals. Another study reported that annual surveillance is sufficient for patients with type 1 gastric NETs $<10 \mathrm{~mm}^{4}{ }^{4}$ In 2012, National Comprehensive Cancer Networks recommended that type 1 gastric NETs with tumor size less than $20 \mathrm{~mm}$ be managed by surveillance with optional EMR. ${ }^{16}$ In 2013, the North American Neuroendocrine Tumor Society guidelines for the treatment of NETs suggested surveillance or endoscopic removal for type 1 gastric NETs less than $1 \mathrm{~cm}$ in size. ${ }^{8}$ For 1- to 2-cm sized (up to 6 polyps) tumor, surveillance with repeat endoscopy every 3 years or endoscopic resection was recommended. In cases of tumors larger than $2 \mathrm{~cm}$, endoscopic resection or surgical resection was recommended. In our study, 67 patients (71.3\%) with NETs were treated by endoscopic resection. In 53 patients (79.1\%) in the ER group, tumors were clearly resected, but $14 \mathrm{pa}^{-}$ tients $(20.9 \%)$ showed local recurrence on follow-up. In the EMR sub-group, incomplete resection was performed in 9 patients, and one patient was diagnosed with recurrence on follow-up. This patient underwent wedge resection, and no further recurrence was noted. In the polypectomy sub-group, incomplete resection was also observed in one patient. This patient then underwent EMR, and no tumor was noted at follow-up endoscopy. Tumor size greater than $10 \mathrm{~mm}$ was observed in 8 patients (11.9\%) in the ER group. Even in patients with tumor size greater than $10 \mathrm{~mm}$, most (7 patients) showed no recurrence at follow-up. No significant risk factors for tumor recurrence were found.

Recently, a few studies have examined NET treatment outcomes without removal. In one such study, 88 patients with multiple carcinoid tumors, usually not more than 1 $\mathrm{cm}$ in diameter, associated with type A gastritis were enrolled. ${ }^{17}$ Of these patients, 98\% were followed up clinically or by endoscopy and biopsy without removal. The metastasis rate was 0\%, and the age-corrected KaplanMeier survival rate was normal life expectancy. Another study reported on 8 patients with multiple gastric carcinoids smaller than $20 \mathrm{~mm}$ associated with type A gastritis who were observed for 1.5 to 10.8 years. ${ }^{18}$ Without removal of the carcinoid tumors, these patients were free of the development or metastasis of carcinoids. In our study, 27 patients with NETs were observed without treatment. Among these patients, tumor progression occurred in 8 patients $(29.6 \%)$, but no evidence of tumor progression was found in 19 patients (70.4\%). In this OB group, tumor size greater than $10 \mathrm{~mm}$ was seen in 4 patients (14.8\%), and only 1 patient showed tumor progression. No mortality was reported in either group during follow-up.

Although many studies differ in criteria, tumor size has been recognized as an important factor for determining treatment. However, analysis of tumor size in the ER and OB groups in our study revealed that tumor size is not a contributing factor for recurrence $(P=0.245)$ or tumor progression $(P=0.976)$ in type 1 gastric NETs that are confined to the submucosal layer and exhibit no lymphovascular invasion or metastasis. Considering that the tumor recurrence/progression ratio showed no significant differ- 
ence in either modality group, observation without treatment appears to be a useful option for type 1 gastric NETs.

Our study has some limitations. First, we retrospectively enrolled patients according to the WHO 2000 system for NET classification; thus, we could not evaluate tumor histology on the basis of proliferative activity, such as determined by the Ki-67 index or mitotic rate. Also, follow-up duration was relatively short and was not randomized properly. Second, due to the retrospective design, the study had a possible selection bias. Lastly, differences might have occurred in the outcomes of the endoscopic resections and selection of methods for endoscopic resection due to different policies of each center.

In conclusion, on the basis of our study's outcome and because of the low potential for tumor progression, we suggest that observation without tumor resection in type 1 gastric NETs without risk factors is a reasonable treatment option.

\section{REFERENCES}

1. Merola E, Sbrozzi-Vanni A, Panzuto F, et al. Type I gastric carcinoids: a prospective study on endoscopic management and recurrence rate. Neuroendocrinology 2012;95:207-213.

2. Scherübl H, Cadiot G, Jensen RT, Rösch T, Stölzel U, Klöppel G. Neuroendocrine tumors of the stomach (gastric carcinoids) are on the rise: small tumors, small problems? Endoscopy 2010; 42:664-671.

3. Delle Fave G, Capurso G, Milione M, Panzuto F. Endocrine tumours of the stomach. Best Pract Res Clin Gastroenterol 2005;19:659-673.

4. Ruszniewski P, Delle Fave G, Cadiot G, et al; Frascati Consensus Conference; European neuroendocrine Tumor Society. Welldifferentiated gastric tumors/carcinomas. Neuroendocrinology 2006;84:158-164.

5. O'Toole D, Delle Fave G, Jensen RT. Gastric and duodenal neuroendocrine tumours. Best Pract Res Clin Gastroenterol 2012; 26:719-735.

6. Klöppel G, Perren A, Heitz PU. The gastroenteropancreatic neuroendocrine cell system and its tumors: the WHO classification. Ann N Y Acad Sci 2004;1014:13-27.

7. Sato Y, Imamura H, Kaizaki Y, et al. Management and clinical outcomes of type I gastric carcinoid patients: retrospective, multicenter study in Japan. Dig Endosc 2014;26:377-384.

8. Kunz PL, Reidy-Lagunes D, Anthony LB, et al; North American Neuroendocrine Tumor Society. Consensus guidelines for the management and treatment of neuroendocrine tumors. Pancreas 2013;42:557-577.

9. Endoscopic Classification Review Group. Update on the paris classification of superficial neoplastic lesions in the digestive tract. Endoscopy 2005;37:570-578.

10. Solcia E, Klöppel G, Sobin LH, et al. Histological typing of endocrine tumours. New York: Springer, 2000.

11. Rindi G, Arnold R, Bosman FT, et al. Nomenclature and classification of neuroendocrine neoplasms of the digestive system. In: Bosman FT, Carneiro F, Hruban RH, Theise ND, eds. WHO Classification of tumors of the digestive system. 4th ed. Lyon: International Agency for Research on Cancer, 2010:13-14.

12. Niederle MB, Hackl M, Kaserer K, Niederle B. Gastroenteropancreatic neuroendocrine tumours: the current incidence and staging based on the WHO and European Neuroendocrine Tumour Society classification: an analysis based on prospectively collected parameters. Endocr Relat Cancer 2010; 17:909-918.

13. Ichikawa J, Tanabe S, Koizumi W, et al. Endoscopic mucosal resection in the management of gastric carcinoid tumors. Endoscopy 2003;35:203-206.

14. Delle Fave G, Kwekkeboom DJ, Van Cutsem E, et al; Barcelona Consensus Conference participants. ENETS Consensus Guidelines for the management of patients with gastroduodenal neoplasms. Neuroendocrinology 2012;95:74-87.

15. Niederle MB, Niederle B. Diagnosis and treatment of gastroenteropancreatic neuroendocrine tumors: current data on a prospectively collected, retrospectively analyzed clinical multicenter investigation. Oncologist 2011;16:602-613.

16. Kulke MH, Benson AB 3rd, Bergsland E, et al; National Comprehensive Cancer Networks. Neuroendocrine tumors. J Natl Compr Canc Netw 2012;10:724-764.

17. Rappel S, Altendorf-Hofmann A, Stolte M. Prognosis of gastric carcinoid tumours. Digestion 1995;56:455-462.

18. Hosokawa O, Kaizaki Y, Hattori M, et al. Long-term follow up of patients with multiple gastric carcinoids associated with type A gastritis. Gastric Cancer 2005;8:42-46. 